\title{
Ragam Bahasa Indonesia Tentara Nasional Indonesia Angkatan Darat: Kajian Psikolinguistik
}

\author{
Ni Kadek Nita Wiryandani", I Nyoman Suparwa, Anak Agung Putu Putra. \\ Prodi Sastra Indonesia, Fakultas Ilmu Budaya, Unud \\ [nitawiryandani96@gmail.com],[nym_suparwa@unud.ac.id],[putraharini@yahoo.com] \\ Denpasar, Bali, Indonesia \\ *Corresponding Author
}

\begin{abstract}
This research entitled "Indonesian Language Variety of the Army; Psycholinguistic studies". The way it expess are also in firm, solid, and clear manner. This research is the background of the author to conduct a research on the diversity of languages applied in the military. The aims of this research is to describe and understand the use of language in the military. The method used in this study is descriptive qualitative research method, interview techniques, and oral direct communication with students and military teachers. The implication of this study on linguistics knowledge is that on psycholinguistic study, to find out the mentality of a student while studying at Rindam IX/Udayana.
\end{abstract}

Keywords: psycholinguistic, language variety, army.

\begin{abstract}
Abstrak
Penelitian ini berjudul "Ragam Bahasa Indonesia Tentara Nasional Indonesia Angkatan Darat: Kajian Psikolinguistik". Bahasa yang ada dalam dunia militer dikenal dengan kebakuannya, keformalannya, dan memiliki identitas dari penuturnya. Cara mengungkapkannya juga dengan cara sangat tegas, padat, dan selalu jelas lantang. Penelitian ini melatarbelakangi penulis untuk melakukan analisis terhadap keragaman bahasa yang diterapkan di kalangan militer. Tujuan penelitian ini mendeskripsikan dan memahami penggunaan bahasa di kalangan militer. Metode yang digunakan, yakni metode penelitian kualitatif deskriptif, teknik rekam, wawancara, dan terlibat komunikasi langsung secara lisan dengan siswa dan gumil. Hasil penelitian ini menjelaskan ragam bahasa dan tentara. Implikasi penelitian ini terhadap ilmu linguistik, yaitu psikolinguistik dapat mengetahui mental seorang siswa saat berpindidikan di Rindam IX/Udayana.
\end{abstract}

Kata kunci: psikolinguistik, ragam bahasa, tentara.

\section{Latar Belakang}

Tentara adalah lascar, prajurit: tentara dapat diperintahkan menjaga bangunanbangunan yang vital; pasukan (dari orang-orang berkewajiban berperang): tentara diterjunkan di daerah musuh melalui udara; kesatuan alat negara yang terdiri atas orang-orang terlatih dapat 
berperang; lain kata tempur itu berbaris dengan tegapnya; orang yang menjadi anggota Tentara Nasional Indonesia, yaitu Prajurit, Bintara, Perwira, dan sebagainya; militer; sesuatu dapat berhubungan (bertalian) dengan angkatan bersenjata (misalnya hukum; pendeta) (KBBI, 2005: 556).

Resimen Induk Komando Daerah Militer atau RINDAM yang dilakukan di Kediri, Tabanan, Bali merupakan lembaga untuk pendidikan siswa bagi calon tentara yang disebut Tamtama dan tentara yang disebutBintara Angkatan Darat serta Kolat Bela Negara bagi instansi swasta lain. Penulis melakukan penelitian untuk menganalisis Ragam Bahasa Indonesia Tentara Nasional Indonesia Angakatan Darat secara lisan dan tulis. Dalam bahasa Indonesiaditingkat pelajar (sebutan Dikmaba bagi siswa Bintara dan Dikmata bagi siswa Tamtama), Tamtama hingga Bintara.

Psikolinguistik merupakan bidang interdisipliner sehingga termasuk ke dalam bidang makrolinguistik (Kridalaksana, 1982).

Kaidah perubahan bahasa pada proses mental seorang militer dapat dilihat dari struktur lahir (surpace structure) dan struktur batin (deep structure). Struktur lahir artinya output dari transformasi dan input komponen analisis fonologi. Struktur batin artinyaoutput dari kaidah struktur dari frasa dan leksikon serta input pada transformasi dan komponendari analisis semantis; biasanya didasari pada kalimat atau suatu frasa. Sebelum istilah psikolinguistik atau psikologi bahasa diperkenalkan, sudah beberapa kali muncul tulisan sebagai hasil pemikiran yang terkait dengan bahasa dan jiwa/mental.

\section{Pokok Permasalahan}

Pokok permasalahan yang ada dari latar belakang diatas sebagai berikut. a. Bagaimanakah ragam bahasa Indonesia Tentara Nasional Indonesia Angkatan Darat?

b. Bagaimanakah kaidah perubahan bahasa dari struktur batin ke struktur lahir bahasa Tentara Nasional Indonesia menurut transformasi generatif?

c. Bagaimanakah proses pembelajaran bahasa pada pendidikan Tentara Nasional Indonesia Angkatan Darat?

\section{Tujuan Penelitian}

Tujuan umum dari penelitian inipenting bagi seorang anggota militer TNI AD untuk lebih mengenal bagaimana pentingnya bahasa Indonesia yang dapat digunakan secara baik dan benar untuk dipelajari dan dipahami perkembangannya. Tujuan khusus penelitian ini,yakni dapat mengetahui ragam bahasa, kaidah perubahan bahasa dari struktur batin ke struktur lahir, dan dapat mengetahui proses pembelajaran bahasa pada saat pendidikan tentara yang dilakukan di pusat pelatihan Rindam IX/Udayana Kediri Tabanan, Bali.

\section{Metode Penelitian}

Dalam analisis penelilitianini menggunakan metode kualitatif, yaitu metode dengan cara menafsirkan dan menyajikan hasil penelitian dalam bentuk deskripsi. Adapun ulasan ketiga metode, pertama, menggunakan metode dan teknik pengumpulan data diantaranya, metode simak dengan teknik libat cakap dan teknik rekam. Kedua, metode dan teknik analisis data berupa audio. Ketiga, metode dan teknik penyajian hasil analisis data,yaitu metode informal merupakan penyajian data.

Khususnya metode informal pada analisis bentuk situasi psikolinguistik yang menyatakan ragam bahasa yang terjadi di pendidikan Tentara Nasional Indonesia Angkatan Darat. Metode informal pada analisis ungkapan verbal 
yang merupakan singkatan, tegas, jelas dan padat pada siswa tamtama dan bintara saat berkomunikasi dengan gumil saat pendidikan.

\section{Hasil dan Pembahasan}

\subsection{Fonologi}

Fonologi merupakan cabang dari linguistik yaitu ilmu bahasa yang mengkaji bunyi-bunyi bahasa, dari proses terbentuknya dan perubahannya. Fonologi mengkaji bunyi bahasa secara umum dan fungsional (Chaer, 2007:24).

\section{a. Bunyi}

Bunyi bahasa merupakan bunyi yang terdiridari perwujudan setiap bahasa yang dapat dihasilkan oleh alat ucap manusia, sehingga dapat berperan dalam ucap manusia (Chaer,2013:26).

\section{b.Klasifikasi Bunyi Segmental dan Suprasegmental}

Klasifikasi bunyi segmental didasarkan atas banyak macam kriteria, yaitu ada tidaknya gangguan, pita suara, mekanisme artikulasi, dan tinggi rendahnya lidah. Klasifikasi ini dapat dilihat dari contoh tekanan yang ada. Tekanan yang menyatukan arti kera lembutnya suatu bunyi. Contoh dari data instansi militer yaitu:

Data [4] $/$ senjata $/=$ sen + jata

Gumil : istri pertama tentara adalah senjata, jelas ini?

Siswa : siap!jelas!

Data [5] /senior/ $=$ sen+ior

Gumil : senior tidak akan salah, jika juniornya tidak salah juga, jelas ini?

Siswa : siap!jelas!

\section{Analisisnya:}

Temuan data dapat dilihat pada kata senjata dan kata senior. Jika kata senjata dan senior diberikan tekanan pada kata sen, maknanya adalah pengertian dari keuangan yang dapat diartikan sebagai suatu ukuran moneter yang setara dengan 1/100 dari satuan dasar dan setara dengan koin senilai 1 sen.

\subsubsection{Morfologi}

Morfologi merupakan bagian dari ilmu bahasa yang dapat dipelajari seluk-beluk kataperubahan bentuk, kata terhadap arti bahasa dan golongan setiap kata (Putrayasa,2008:3).

Proses morfologi terdiri atas beberapa macam, yaitu proses pembubuhan afiks (afiksasi), komposisi atau pemajemukan, dan pengulangan (reduplikasi).

Data [26] 'senjata' kata dasar

Gumil :Mari kita ulas kembali, pembahasan mengenai senjata ringan, yaitu N16 dan SS1

Siswa : siap!

Data [27] 'bersenjata' kata berimbuhan Gumil :posisi bersenjata yang baik dalam penyamaran, yaitu merayap! jelas ini?

Siswa : siap!jelas!

\section{Analisisnya}

Analisis kata diatas,disebabkan oleh perubahan kata. Arti kata bersenjata dan senjata yang berarti senjata benda yang memiliki anak peluru sebagai perlindungan diri bagi prajurit. Bersenjata mendapatkan kata berimbuhan [ber]senjata artinya kegiatan menggunakan senjata untuk berperang.

\subsubsection{Sintaksis}

Sintaksis merupakancabang dari linguistik yang dapat membahas internal kalimat, pendapatdari (Manaf, 2009:3). Struktur internal kalimat dapat dibedakan menjadi frasa, klausa, dan kalimat untuk pembahasan selanjutnya. 
Kalimat juga dapat dibedakan menjadi dua jenis, yaitu kalimat tunggal (satu) dan kalimat majemuk (dua). Kalimat tunggal merupakan kalimat terdiri atas satu inti kalimat atau satu klausa. Sebaliknya, kalimat majemuk adalah kalimat yang mempunyai dua pola atau lebih dari dua pola. Kalimat majemuk juga dapat dibagai menjadiinduk dari kalimat dan anak dari kalimat.

Kalimat juga dapat dibagi lagi menjadi tiga jenis kalimat, yaitu kalimat yang disebut berita, kalimat yang disebut perintah dan kalimat yang disebuttanya. Kalimat perintah adalah kalimat yangmenugaskan seseorang untuk melakukan sesuatu yang dikehendakinya atau perintah khusus yang dapat terjadi di instansi militer. Kalimat yang terjadi dalam instansi militer untuk menerapkan kesantunan dan taat dalam disiplin, yaitu kalimat perintah. Kalimat perintah yang ada dalam instansi militer dapat dilihat dari contoh berikut.

Data [43]

Gumil : siswa nomor helm 124, ambil pasukan!

Siswa : siap!

Data [44]

Gumil :saat makan pun, siswa tidak ada yang berbicara di meja makan, jelas ini?

Siswa : siap, jelas!

\section{Analisisnya}

Kalimat diatas menunjukkan kalimat perintah seorang gumil untuk siswa.Gumil memberikan perintah kepada siswa agar siswa dapat belajar untuk memimpin pasukan yang ada dalam data nomor 43, dan gumil memberikan perintah ke semua siswa untuk disiplin saat makan bersama di meja makan agar menghemat waktu yang ada.

\subsubsection{Leksikon}

Leksikon dapat mewadahi konsep dari kumpulan beberapa leksem suatu bahasa, yaitu kumpulan secara keseluruhan maupun kumpulan secara sebagian, menurut (Chaer, 2007:2--6).

Sebuah makna yang ada dalam leksikon yaitu kata yang mengalami perubahan kata. Umumnya instansi militer memiliki konteks dari pengucapannya yang tidak tentu, terkadang ucapan gumil saat kegiatan belajar, kadang juga ucapan gumil saat pelaksanaan upacara di kalangan militer, contohnya dalam intansi milliter dapat dilihat sebagai berikut.

Data [46] 'Caraka'

Gumil : kaya semalam, caraka malam, itu ada maksud dan tujuannya. Bukan hanya jalan-jalan terus sampai ditujuan.

\section{Analisisnya:}

Caraka memiliki arti sebagai pengantar surat. Kalimat diatas,caraka dijadikan kegiatan rahasia belanegara untuk memecahkan suatu pos tujuanyang dilakukan malam hari.Kata caraka juga bisa digunakan dalam keseharian di lingkungan dinas sipil, tetapi tidak bersifat sangat rahasia. Dalam instrasi sipil dapat diketahui masyarakat sipil saat mengantar surat ke instansi lainnya.

\subsection{Kaidah Perubahan Bahasa dari Struktur Batin ke Struktur Lahir Bahasa Tentara Nasional Indonesia}

Keluarga militer memiliki rasa kedekatan dengan dunia militer pasti sangat tahu bagaimana ujaran yang benar di segala situasi dan kondisi yang ada karena ikatan keluarga.

Kajian struktur batin ke struktur lahir penting untuk pemahaman suatu kalimat karena dapat dilihat dari proses mental seorang tentara yang dilalui oleh siswa 
dalammenanggapi kalimat-kalimat tidak ambigu. Perhatikan kalimat berikut.

Data [93]

Gumil : siswa tertua itu masih dapat menembak sasaran tempur

Data [94]

Danki : siswa dan gumil tertua itu masih dapat menembak sasaran tempur

\section{Analisisnya:}

Dapat diyakini apakah siswa itu tua seperti gumil atau hanya gumil saja yang disebut tua atau melebihi dari umur siswa, sedangkan siswanya tidak. Adanya interpretasi yaitu kata adjektiva dari bertambahnya umur (tua) pada nomina dari gumil dan frasa dari siswa.

\subsection{Proses Pembelajaran Bahasa pada Pendidikan Tentara Nasional Indonesia Angkatan Darat}

Proses pembelajaran bahasa pada pendidikan tentara nasional khususnya Angkatan Darat sangat berbeda dengan di instansi lain. Ragam bahasa formal dapat diterapkan dalam satuan instansi dari interaksi lisan yang terjadi. Keformalan tersebut dapat disertai dengan unsur bahasa tubuh berupa perbuatan/gerakan yang dapat dipraktekkan. Dapat dilihat darisandi norma sosial dalam instansi militer, unsur aturan sosial kehidupan militer, dan pola relasi bagi penerapan kesantunan kepada senior tentara paling atas amaupun satu angkatan jauh. Hal ini dapat menggariskan suatu keformalan dalam berbahasa gumil antar siswa dan kesantunan saat berinteraksi gumil antar siswa, tetapi terdapat juga humor di selasela komunikasi yang terjadi antar gumil dan siswa. Contohnya terdapat di kelas secata dan Susbatih Muda dan kelas bela negara antar mahasiswa atau siswa.

\section{Simpulan}

Berdasarkan analisis data, dalam penelitian Ragam Bahasa Indonesia Tentara Nasional Angkatan Darat di Kediri, Kabupaten Tabanan ditemukan tiga jenis analisis cabang linguistik, yakni fonologi, morfologi, sintaksis, dan pelengkap membahas leksikon. Pertama, cabang linguistik fonologi membahas bunyi dan klasifikasi segmental dan suprasegmental untuk menganalisis kata dalam komunikasi gumil dan siswa. Kedua, morfologi membahas dari selukbeluk suatu kata serta terjadi perubahan bentuk kata terhadap suatu arti dan golongan sebuah kata, di antaranya proses pembubuhan afiks (afiksasi), komposisi atau pemajemukan dalam bahasa Indonesia, dan pengulangan (reduplikasi). Ketiga, sintaksis membahas struktur internal kalimat, yaitu kalimat tunggal (satu kalimat), kalimat majemuk (dua unsur kallimat), kalimat berita (informasi), kalimat perintah (suruhan) dan kalimat tanya (bertanya). Hal ini dalam kajian sintaksis yang dapat diterapkan adalah kalimat perintah sebab saat pendidikan siswa tamtama dan bintara untuk menguji mental bakal calon tentara adalah siap menjalankan perintah.Pelengkap leksikon membahas makna dari suatu kata sebelum mengalami proses perubahan bentuk.

\section{Daftar Pustaka}

Chaer, Abdul. 2003. Linguistik Umum. Jakarta:Rineka Cipta.

Chaer, Abdul. 2007. Kajian Bahasa:Struktur Internal, Pemakaian dan Pemelajaran. Jakarta: Rineka Cipta.

Manaf, Ngusman Abdul, 2009. Sintaksis: Teori dan Terapannya dalam Bahasa Indonesia. Padang: Sukabina Press. 
Moelino, Anton M. \&Soejono,

Dardjowidjojo. 1988. Tata Bahasa

Baku Bahasa Indonesia. Jakarta:

Departemen Pendidikan dan

Kebudayaan Republik Indonesia. 